\title{
The metaphysics of perception: enactivism, phenomenology and information.
}

\author{
David Rose \\ School of Psychology, University of Surrey, Guildford, Surrey GU2 7XH, U.K. \\ emaildaverose@cantab.net
}

\begin{abstract}
Enactivism is a major research programme in the philosophy of perception. Yet its metaphysical status is unclear, since it is claimed to avoid both idealism and realism yet still has aspects of both within it. One attempt to solve this conundrum is based on the fusion of enactivism with phenomenology and the mathematical concept of symmetry breaking (Moss Brender, 2013). I suggest this is not entirely successful and propose it needs the addition of a multi-level, non-reductive metaphysics (for example, Informational Structural Realism). The processes we commonly call 'perception' are causal transfers of information at certain levels in the hierarchy of meaningful structures that comprise physical reality. Phenomenologists could use the word 'perception' metaphorically across all levels, although realists need not do so.
\end{abstract}

Keywords. Phenomenology, enactivism, embodiment, realism, idealism, metaphysics, philosophy of perception, continental philosophy, information, structural realism, systems theory 


\section{The metaphysics of perception}

In recent years there has been debate within the perception literature between phenomenologists and scientific realists, for example over the status of illusions. (For reviews see: Maniatis, 2015; Rose \& Brown, 2015; Rose, 2018, in preparation-a, -b; Gomez-Marin, 2020; Todorović, 2020.) Thus illusions are commonly defined as deviations of our percepts from the veridical representation of objective reality — but this requires there being a singular ground truth about that reality, or 'what is out there', which our percepts should in some way represent or match. But the existence of any such external standard is denied by phenomenologists, who therefore dispute the possibility of both veridical perception and its failure in illusions. On the long view, this is a manifestation of the millennia-old debate between metaphysical realism $^{1}$ and anti-realism (reviewed by McMahon, 2001; Braver, 2013; Pagden, 2013; Sebold, 2014; Wolin, 2019). In a survey of the last century (Rose, 2021), I argued that the cognitive sciences, neuroscience and Gibsonianism fall within the realist camp, while continental phenomenology has its roots in anti-realism, and is thus in danger of sliding into idealism, motivated by anti-scientific attitudes and the fear of nihilism. $^{2}$

Here, I consider some compromise or hybrid solutions, which might dissolve if not solve the disagreement between these extreme alternative worldviews. As entry point I take the perceptual theory of enactivism or embodiment, the idea that perception can only be understood as part of a sensorimotor loop between motile organism and environment (for collections of articles see Coello and Fischer, 2016; Silverman, 2016; Ward et al., 2017; Kirchhoff, 2018; Newen et al., 2018; Isaac \& Ward, 2021; and Silva \& Ferreira, 2021). ${ }^{3}$ This makes common sense, yet its metaphysical position is ambiguous. Although it sounds like a perfectly straightforward realist ontology - organisms move and evolve in a physical environment, developing an extended mind with broad teleofunctional ${ }^{4}$ content (Wright, 1973; Millikan, 2004, 2017; Rose, 2006, ch. 5; 2012a; Sims, 2021a, 2021b) - links are often made

\footnotetext{
${ }^{1}$ The distinction between continental and analytic philosophy is controversial, but I will continue to use it here as a convenient shorthand (see Rose and Brown, 2015, and Rose, 2021, for further discussion).

${ }^{2}$ For example, Sparrow (2014, ch. 2) argues that talk about 'embodiment', 'praxis' and 'lifeworld' is merely part of the "rhetoric of concreteness" (p. 69) that phenomenologists use in their attempts to distance themselves from idealism - to prevent themselves from being "seduced by antirealism" (Sebold, 2014, p. 248). (There has of course been controversy over this point, which is discussed in Rose, 2021.)

${ }^{3}$ For brevity, I'm treating enactivism, embodiment, sensorimotor and embedded as synonyms for the same (family-resembling) class of theories, despite the terminological nuances (e.g. Shapiro, 2011; Ward et al., 2017; Newen et al., 2018; Schlicht \& Starsak, 2021).

${ }^{4}$ Teleofunctionalism is one way analytic philosophy accounts for meaning: as evolved Darwinian functionality. Consciousness is explained or grounded as intentionality (aboutness), intentionality as function or purpose, function as teleology and teleology as evolutionary (or ontogenetic) history.
} 
between embodiment and phenomenology (e.g. see Kee, 2021). The latter trail leads through Heidegger, to Merleau-Ponty, to Maturana and Varela (e.g. 1980) and on to Thompson (2007). Although this development is intended, and explicitly claimed, to avoid both idealism and realism (for example by Wagemans, 2015), if taken to its conclusion phenomenology still collapses into an almost Berkeleyan idealism. A revealing example is a prize-winning essay from Moss Brender (2013).

\section{The meaning of enactivism}

Moss Brender (2013) first criticizes both Merleau-Ponty and Thompson for leaving an "ambiguity", in that physical form in nature was claimed both to pre-exist and to be the consequence of conscious perception. Moss Brender says: "Once again, we find ourselves vacillating between these two incompatible standpoints: the physical order is simultaneously meaningless in itself, and meaningful for us" (p. 265). ${ }^{5}$ However, Moss Brender says, those writers did not explain how meaning arises 'for us'. His paper sets out to answer that question.

Now, 'meaning' plays a central role in continental philosophy. This reflects its metaphysics, in which not just consciousness but indeed everything in existence is intimately dependent upon intentionality ('aboutness'). Enactivism reduces intentionality to relationships between entities, with at least one of those being a motile body. An entity (which Moss Brender refers to as a form, Gestalt, or orderly structure) can be "conceived" by another entity only because one of them moves relative to the other, thus according to Moss Brender 'breaking symmetry', ${ }^{6}$ creating a 'point of view' and thus "sense".

\footnotetext{
${ }^{5}$ A similar schism is also seen in the perception debates, for example in claims that perception is limited to what can be sensed by a motile organism from its own point of view, yet the organism is simultaneously described as having evolved in a real and objective environment (e.g. Maniatis, 2015; Gomez-Marin, 2020).

${ }^{6}$ Mathematically, symmetry is defined as insensitivity to transformation. For example a circle can be rotated by any amount and still be exactly the same shape. Reflections about any of its infinite number of diameters also yield the same result. If we view the circle from a slightly different location however (except along its axis or from the side) its image becomes (roughly) elliptical, and ellipses only retain their shape when rotated by (multiples of) 180 degrees, or when reflected across their major or minor axes. Thus ellipses have 'broken' or reduced symmetry relative to circles, or in other words ellipses are more asymmetrical, interesting and informative (information-bearing). Circles themselves also carry information by having a location, whereas a uniform Ganzfeld doesn't. This makes Being (information, pattern or shape) complementary to uniformity rather than to nothingness. Moss Brender's (2013) interpretation is that asymmetries in the environment are revealed by (certain kinds of) movement of the (entity's) viewpoint. These are asymmetries that make a difference to/for an entity, and they comprise potential for further action.
} 
Note that this ambiguous term ('sense') is taken to mean both perception and understanding/meaning. Kant's distinction between noumena and phenomena transformed (or regressed) in some strands of continental philosophy into the view that only the (intentional) connection between mind and object exists, and is thus the fundamental metaphysical unit of the universe. Thus, under these developments of continental phenomenology it is not just that perception and cognition are inseparable (fused, synonymous) but that ontology and epistemology are too, so nothing can exist unless it is known/perceived (i.e. esse est percipi). (See also footnote 11 below; Bhaskar, 1975; Meillassoux, 2006; Elder-Vass, 2012, pp. 244-250).

However Moss Brender goes on to suggest that although nature is "perceptual" it is not (necessarily) "dependent on a mind or a subject" (p. 271). The same general principle is proposed to apply at all levels of nature, including the physical (thus: "physicochemical phenomena are best understood not as synthetic wholes composed of atomic parts, but rather as differences or asymmetries, which do imply a point of view.": p. 271). Differences in nature are only 'conceivable' because there are moving entities that reveal the difference and thus create sense. These motile entities are themselves created by autopoietic (self-organizing) symmetry breaking in nature, by which parts and whole mutually constrain each other to form a particular entity. Sense is primordial in nature (in that all else is derived from it), discovered by humans as "always already" present in the world. It comes in degrees rather than being all or none, depending how complex an organism you are.

So, Moss Brender concludes (p. 273):

"In overcoming Cartesian ontology, we will also overcome the opposition between philosophy and the natural sciences, assigning them both a single project: not to discover the real world behind the world that we perceive, but to allow nature to educate our powers of perception."

\subsection{Commentary}

To look at Moss Brender more critically, however, let me first quote part of his concluding summary (p. 272). He states:

"A nature that can only be known from the outside cannot truly be known at all, but only mastered and controlled."

But how can we master and control something if we do not 'know' it (near-) veridically? Presumably, in this context "known" specifically means having a feeling of empathy, since for phenomenologists 'knowing' means the sharing of empathic 
'resonance' between living bodies (e.g. Thompson, 2007, p. 165) ${ }^{7}$ rather than the possession of factual knowledge. Moss Brender continues (my italics):

"It [i.e. nature known from outside] has no meaning of its own, and so can only have a meaning imposed upon it. To reject this ontology is to affirm that nature has its own endogenous sense which is not constituted by consciousness. It is precisely this nascent meaning that we have discovered in the phenomenon of asymmetry. The autoproduction of sense in nature takes place through symmetrybreaking, in which natural wholes articulate themselves into parts or regions, creating differences out of indifference and form out of uniformity. These differences are neither things nor ideas, neither atoms nor artefacts. They cannot be known by a disembodied mind, but only perceived by a living body. The scientist who seeks a causal explanation for the complex forms she observes in nature is thus engaged in a perceptual project."

A few sentences later Moss Brender says (p. 273):

“... mechanical science ... has decided in advance how nature is to be divided, in terms drawn from human techne rather than from the observation of nature itself. It is thus a perceptual stance that refuses to be educated by the world that it perceives."

But where does human 'techne' come from? Does practical science and action not develop from and depend centrally upon observations of nature? ${ }^{8}$ I suspect practitioners of 'mechanical science' would simply disagree with Moss Brender here.

Further, Moss Brender's theory is ambiguous about the nature and role of symmetrybreaking. Thus on the one hand it claims that whole-part autopoiesis in the creation (i.e. morphogenesis) of a particular natural entity is a process of symmetry-breaking. On the other hand it then also describes the creation of sense from a point of view, by and thus for a moving observer, as symmetry-breaking. Yet these processes are surely different in kind, in that only the latter is analogous to perception.

\footnotetext{
${ }^{7}$ Thompson's (2007, ch. 13) more detailed account of the origins of consciousness simply amounts to Good-Old-Fashioned top-down cultural/social constructivism.

${ }^{8}$ Dismissing scientific observations as mere "pointer readings" (as does Koenderink, 2014, p. 5, after Eddington, 1928, and the British idealists) is picturesque but unconvincing. Does breaking open a rock and finding a fossil, or looking up to see Halley's comet, count as a pointer-reading? How about what we see through spectacles, magnifying glasses, light microscopes, phase-contrast microscopes ... where is the boundary between "the observation of nature itself" and reading an instrument? (For further discussion of the choices we have on this point see Chakravartty, 2017, pp. 205-214.) As Ladyman and Ross (2007, p. 253) put it, in reply to Eddington: "Entities like stars, or a macroscopic sample of a gas, are both observable and theoretical."
} 
Next and most crucially the theory proposes that nature, in the form of asymmetries manifest as whole-part structured entities ("natural wholes"), exists before a living body (also a natural whole) perceives those entities from its point of view. But this concedes the very point that realists have been claiming all along, namely that entities can and do exist without being perceived. ${ }^{9}$ So how can nature be described purely as "perceptual"? For instance Moss Brender (2013, p. 271; my italics) says:

"... the concept of asymmetry gives us the language which Merleau-Ponty lacked to describe nature as perceptual without making it dependent on a mind or a subject"

Thus Moss Brender claims to have avoided idealism. However it is not clear what he means here, since he does not define 'mind'. Presumably he means anything disembodied or disembodiable, thus merely excluding substance dualism or the extreme (strong AI) form of computational functionalism - which few philosophers or scientists believe in these days anyway. But this purported replacement, elimination or assimilation of the mental level into the perceptual does not convince or satisfy. A simple feedback loop between a motile individual and its environment does not capture the complexity of the internal processing that occurs inside complex creatures, nor the non-linear system dynamics that occur within well-evolved brains that give rise to emergent properties which are not (necessarily) 'like' perception. I am here merely repeating the Gestalt theorists' point that the whole can be greater than - or qualitatively different from - the sum of its parts. ${ }^{10}$ Therefore radically new concepts with novel emergent properties can coalesce from systems of percepts. (We might call this process 'mental', or at the mental level, or in the mind - but if you prefer, you can read 'mental' as 'cognitive'; my use of 'mental' and 'mind' does not imply dualism.) Thus our knowledge and imagination are not constrained in any linear fashion by what we can "possibly" perceive, as (some) phenomenologists say they are (e.g. Koenderink, 2014, p. 5).

\footnotetext{
${ }^{9}$ A similar point against enactivist anti-realism in general has been made by Maniatis (2015), and even earlier by von Bertalanffy (1955) in refutation of von Uexküll's (1909) constructivist thesis which Koenderink (2014) has recently cited approvingly. Similarly, Escobar (2012, p. 66, original italics, citing Zolo, 1990, for support) has argued against the autopoiesis of Maturana and Varela (1980): "They repeatedly claim that everything said is said by an observer ... which implies there is no such thing as a completely objective observation. The observer always constructs his or her own reality; thereby the question about what reality is in itself is meaningless. The only meaningful question is what reality is for a given observer. This radical epistemological constructivism becomes problematic, however, because the theory of autopoiesis does not attempt to be a theory of what a living system is for a given observer, but rather ... for any possible observer. For that reason, it is rather perplexing that Maturana and Varela forget their realist commitments, even criticizing realism as such, and focus mainly on the constructivist ones."

${ }^{10}$ Gestalts may in another sense be less than the sum of their parts, in that the internal relationships act as constraints and so reduce the degrees of freedom or ambiguity of meaning of the parts (cf. broken symmetry); see more on this below ( $\$ 3.4$ and $\S 4)$.
} 
So in the end, scientific realists can still deny that ontology is epistemology (e.g. Bhaskar, 1975; Sankey, 2008; Bryant, 2011) and that concepts are restricted only to percepts. ${ }^{11}$ Realists can then accept the enactivist premise (that organisms co-evolve with their environments), and deal accordingly with the separate question of an organism's epistemological abilities — whether it develops concepts of its environment that are (approximately) veridical or speculative and whether these involve meanings, affordances, essences, information, isomorphisms, templates, prototypes, minimal codes, 'equipment', categories, representations, arbitrary symbols or whatever. Enactivism is entirely consistent with ontological realism. It is complementary to cognitive science, not a replacement or alternative theory (see also Shapiro, 2011; Stendera, 2015; Clark, 2016; Clowes \& Mendonça, 2016; Fabry, 2018; Korbak, 2021; Pezzulo \& Sims, 2021; Schlicht \& Starsak, 2021).

Cognitive mechanisms must necessarily arise in addition to affordance processes, for example to cope with radically novel stimuli and environments (a.k.a. the weird and the wonderful), to structure motor planning and navigation hierarchically in complex situations (Cooper \& Shallice, 2000; Millikan, 2004; Coates, 2007; Matthen, 2014; Clowes \& Mendonça, 2016; Schlosser, 2018), to anticipate, evaluate and choose flexibly between alternative courses of potential action or inaction (Schlicht \& Starzak, 2021; Sims, 2021b), to think about counterfactuals and for thought and language to exhibit compositionality, generativity and systematicity (Fodor \& Lepore, 2002).

Thus phenomenology, enactivism, cognitive science and realism can all be integrated, provided we revise and refine our understanding of exactly what perception, cognition and mind are. But to do that we need first to define our terms clearly for each other rather than just using them without explanation as we customarily do within our own self-affirming cliques, in-groups and 'invisible colleges'.

\section{The reality of metaphysics}

The fundamental issue in the metaphysics of perception is, as Blackmore (2002, p. 17) asked, "What is all this stuff around me; this stream of experiences that I seem to be having all the time?" If we accept all the above, then the 'stuff' could just as well be called 'sense' or 'meaning' — rather than 'mind(s)' or 'matter'. It is all the one

\footnotetext{
${ }^{11}$ As Sebold (2014, p. 252) points out, continentals habitually and incautiously substitute talk about concepts with talk about the objects those concepts are about - in other words they always already presume epistemology is ontology (see also Sankey, 2008, p. 2). For example note the ambiguous way "conceive" and "conceivable" are used in the paragraphs above, in which I have deliberately echoed Moss Brender's usage of those terms.
} 
type of stuff, after all. Indeed Braver (2013) attributes to Nietzsche the idea that without the contrast between subjective and objective there is neither an external world nor an apparent one, in that what there is cannot be described as either. (We might call this the Paradox of Monism.) Presumably, we are left with metaphors and similes, for example that the 'stuff' is 'like' (what we normally understand by the words) matter, mind, force, spirit ... or whatever best fits our current worldview.

One currently popular term for the 'stuff' of the universe is 'information'. This crops up not only in the metaphysics and philosophy of physics (e.g. Ladyman \& Ross, 2007; Floridi, 2011; French, 2014) but also in discussions of panpsychism (the notion that everything, including material at all scales, has mental or experiential properties, even if to a minuscule degree). For example, Seager (2016) argues that the panpsychist, fundamental basis of everything is information at the level of quantum physics (in the sense of David Bohm, i.e. information as guidance rather than causation). ${ }^{12}$ Historically, Skrbina (2005) dismisses there having been any significant cross-fertilization of ideas between panpsychism and phenomenology. However, the similarity between the notions of primordial "nascent meaning" which is alwaysalready present in the world (Moss Brender, 2013, p. 272) and panprotopsychism (Chalmers, 2015) perhaps suggests there could be some convergence between continental and analytic metaphysics here. In sum, the three concepts: panpsychism, information and the (putative) fundamental level of reality, have been suggested all to be referring to the same 'stuff'. (For further discussion see Freeman, 2006; Skrbina, 2009a and Brüntrup \& Jaskolla, 2017; for a contrary view see Heil, 2012.)

Another commonly used term is 'structure'. One branch of analytic metaphysics describes all properties as 'relational', which is to say not intrinsic to any substance or thing. What this means is that nothing exists except in relationship to something else - or that all that exists are relationships. Thus currently there are three varieties of Structural Realism (SR) under debate: Ontic, Epistemic and Informational (e.g. Chakravartty, 2007; Ladyman \& Ross, 2007; Floridi, 2011; French, 2014). Ontic SR posits that all that exists are relationships, Epistemological SR says that there may be 'things' that are related (we may or may not be able to discover anything about these

\footnotetext{
12 There are many types/meanings of 'information' (e.g. Lombardi et al., 2015, 2016; Mingers \& Standing, 2018; Ball et al., 2020). For present purposes we should broadly distinguish information as (i) physically energy, which is intrinsic to the system, message or signal (cf. negentropy), or as (ii) semantic, meaningful content that requires decoding or interpretation by a receiver or perceiver that contains a set of possible meanings whose number is reduced by the message. Ladyman and Ross (2007), Seager (2016), Marshall et al. (2018) and Albantakis et al. (2019) emphasize the latter type - relations between two entities analyzed as a sender and receiver - though with detailed and subtle qualifications we cannot go into here - rather than 'information' as fundamental physical bits which a (somewhat phenomenological/anthropic) observer then interacts with to obtain epistemological 'knowledge'. I will be broadly following the semantic interpretation, emphasizing pattern or distribution rather than amount (see also Appendix).
} 
empirically, but we can at least speculate or reason meaningfully about them), while Informational SR says that not only are the relationships informational but the 'things' or relata are themselves informational structures. As such, reality consists of a series of levels of structures/patterns nested within one another. The connecting relationships between each locus are information 'channels' (Ladyman \& Ross, 2007, pp. 307-309). Thus under Informational SR the following conclusions are supported:

"reality is the totality of information" (Floridi, 2011, p. xiii.)

“ ... the ultimate nature of reality is informational ... mind-independent and constituted by structural objects that are neither substantial nor material ... but cohering clusters of data ... [in the sense of] differences de re, i.e. mindindependent, concrete, relational points of lack of uniformity ... In short, Being and Information conventuntur [are interconvertible]." (Floridi, 2011, p. 340.)

"To be is to be a real pattern ..." (Ladyman \& Ross, 2007, pp. 226, 233, 253)

But an even more fundamental point behind the question "what is all this stuff?" is that it implies there is a single answer - that there is just one fundamental level of reality.

\subsection{Arguments pro a single level}

Some analytic philosophers (from Mach, James, Russell and Eddington to recent thinkers such as Strawson, 2006, and Chalmers, 2015) have posited the 'stuff' everything is made from is phenomenality (experience, sense-data, presence, sensation, ...) and that 'the world of physics' and 'the mental world' are derived from it. This is intended to avoid idealism, materialism, dualism and scepticism (e.g. Seager, 2016, pp. 331-336). ${ }^{13}$

Additionally, Ladyman and Ross (2007) support the idea (which they say is dominant in physics) of there being one basic level, because only thus can all the various sciences and metaphysics be unified, and because they think biology's and social science's belief in emergence and multiple levels is incompatible with that aim. ${ }^{14}$ As

\footnotetext{
${ }^{13}$ The thought that at least some analytics and continentals hold a similar basic worldview after all may seem surprising, but follows from commonalities in their historical origins. Note for example: "Hard as it is to believe now, at the time Mach and James, and to a certain extent Russell, were writing, the dominant philosophical position was some form of idealism." (Seager, 2016, p. 332). Whether Eddington and Russell were (at various times) idealists, panpsychists, neutral monists, dual-aspect monists, etc. is a long and involved issue I won't go into here (for reviews see Freeman, 2006; Chalmers, 2015; McHenry \& Shields, 2016; Seager, 2016; Stubenberg, 2016; Goff, 2017).

${ }^{14}$ Although arguments supporting 'emergence' within physics abound (e.g. Hartmann and Valente, 2011; Glick et al., 2020), Ladyman and Ross (2007) say it depends how you define 'emergence'.
} 
mentioned, Seager (2016) supports a single base level, for example to avoid an infinite regress. So too does Heil (2012) to avoid the problem of how multiple levels can each have causal powers (although Heil is against panpsychism at the fundamental level of stuff). ${ }^{15}$

\subsection{But on the other hand ...}

In principle there might however be more than one basic type of stuff (each not convertible into another), or there might be none at all. What could 'none' mean? It is not to say everything is a grand illusion/hallucination, neither is it to be nihilistic. It is to say there is no single level of fundamental stuff.

How do we know there isn't another level below the putatively 'base' level, i.e. that the type is not further decomposable? For example Floridi (2011) considers it an open possibility that there is no fundamental level and that one could always find a deeper structure of some kind. Although he prefers to think there is a basic level from which all else is derived, and to which we can attribute absolute-ness (for example one where entities being related or simply being different ${ }^{16}$ becomes the same: pp. 353-355), Floridi says it's an open possibility whether there is another level of stuff underlying the putatively fundamental stuff (and other levels below that ...):

"So the basic idea behind [Informational SR] is quite simple: we are [informational organisms] dealing with black-boxes inside a grey-box. ... these qualifications are [level of analysis]-dependent, in the same way as the distinction between being a system and being a component or unit of a system is. A blackbox may be opened, but opening it transforms it into a grey-box, in which more black-boxes may be found. Whether ad infinitum we simply cannot say. It might be Russian dolls (informational objects) all the way in." (Floridi, 2011, p. 371.)

"it's real patterns all the way down" (Ladyman \& Ross, 2007, p. 228.)

"Prices, neurons, peptides, gold, and Napoleon are all real patterns, existing in the same unqualified sense as quarks, bosons, and the weak force." (Ladyman \& Ross, 2007, p. 300.)

This picture in many ways resembles that of general systems theory, which states that every entity is a system composed of parts that are themselves each a system, i.e. a sub-system of the original system (for reviews see Rose, 2006, Hofkirchner \&

${ }^{15}$ I disagree with all these, for reasons too complex to go into here (though some partial explanations occur below).

${ }^{16}$ This would constitute a minimal one bit of (physical) information. 
Schafranck, 2011, and Kesić, 2016).$^{17}$ Dynamic systems theory, complexity and chaos theory are extensions of this worldview. The same principle continues up and down the hierarchy of existence ... perhaps all the way down, ad infinitum; i.e. under this metaphysics there is no ultimate level (Hüttemann, 2003; Schaffer, 2003; Montero, 2006). So Nature - the stuff — is infinitely divisible, there are patterns within patterns, ${ }^{18}$ and these can be revealed endlessly as we investigate in increasingly microscopic detail (although as we descend, the patterns persist for increasingly brief periods too: e.g. Simon \& Ando, 1961; Salthe, 1985; DiFrisco, 2017. $)^{19}$

\subsection{A hybrid theory}

However, current physics proposes there is a lower limit imposed by length/time 'quanta' - the Planck scale - below which we cannot go (e.g. Liang, 2020). If so there could be an ontologically ultimate level which is meaningless, with many levels built above that with progressively higher degrees of sentience/meaning/pattern. It doesn't require one sudden 'miraculous' leap from material to mind (as Skrbina, 2009b, assumes; see also Strawson, 2006), and properties such as meaningfulness or mentality don't have to be possessed by the parts in order to be possessed by a whole, as many anti-emergentists think. ${ }^{20}$

17 Originally proposed by von Bertalanffy (1955) as a realist antithesis to the idealist 'constructivism' of von Uexküll (1909), numerous thinkers have since come apparently independently to the same conclusion (Hofkirchner and Schafranek, 2011).

${ }^{18}$ Thus Nature may be like one of those fractal patterns that you can zoom in and zoom in on without ever exhausting the revelation of further pattern. There is no limit to the precision (number of decimal places) to which you can specify the variables (the initial or boundary conditions) in the fractal's equations.

${ }^{19}$ Skrbina (2009c) sees Nature as dynamic nested hierarchical systems, calling his position a form of "panpsychist dual-aspect monism" (p. 366), or "panrelationism", since all that exists are relationships - an idea he traces back to Leibnitz and others (although without discussing modern Ontic Structural Realism and other far more detailed analyses of relations such as that by Floridi, 2011). He also posits that every single thing is connected to everything else (universal holism), but thus has problems accounting for how things differ and how any thing can have boundaries. Deiss (2009) also favours panpsychism within Nature seen as dynamic nested hierarchical systems all the way down, with both sensory- and memory-like abilities within each system at every level.

${ }^{20}$ Emergence may be of either 'weak' and 'strong' type. Only the latter proposes that higher level qualities are unpredictable in principle (hence 'miraculous'). Instead, under systems theory a variety of weak emergence accounts for how (higher level) entities or phenomena persist. Stability occurs when particular components with particular properties (the lower level) come together in a context in which their combined pattern or organisation (a higher level system) constrains them to remain connected in that way - hence ensuring its own persistence in that context. The upper level system can be predicted in principle if we know all about both the lower level and the context (background or boundary conditions). For recent overviews see Gillett (2016), Guay \& Sartenaer (2016), DiFrisco (2017), Glennan \& Illari (2018), Gibb et al. (2019) and Brooks et al. (2021). 


\subsection{Perceiving reality}

In that case, what is the 'stuff' we see? Firstly, exactly what is each level? You could call it dynamic pattern, geometry, structure, information, meaning .... The best term varies with level - because as new levels of reality emerge their properties are different, i.e. the medium subserving the interactions within level $\mathrm{n}$ depends on the nature of the 'stuff' composing level n-1. The best metaphor to use for the interaction therefore varies with level (e.g. causing, guiding, informing, perceiving, translating, inferring, conversing, etc.). Each may work/apply over a few levels but seems stretched if taken too far. Yet the logical and mathematical principles are the same across all levels.

And secondly, if all is systems - hierarchically nested systems - then which are the levels we see? The answer is that we can see several different levels, and what we call 'the' stuff can vary accordingly. For example we can focus in or out on (selectively attend to) one or several levels (though how we do this is another story...). So a face, for instance, may be 'seen' as feeling sad, a school-friend, male, having brown eyes, deeply pored skin, showing signs of jaundice, and so on, depending on the viewer's interest at the time. Additionally instruments, both physical and conceptual, can extend the range of levels we can perceive. In advancing sciences the process of 'perception' becomes increasingly metaphorical it involves increasingly deeper and more extensive cognitive understanding and intuition. $^{21}$

Information (i.e. the disambiguation of potential meanings) is itself an emergent (Rose, 2012a, 2012b). Information is relative to any given level, i.e. it arises in or from the relationship between two adjacent levels. It emerges as and whenever a higher level forms. ${ }^{22}$ Semantic information also has the power to cause change (Lombardi \& López, 2018; Beni, 2020; Godfrey-Smith, 2020), and since emergent levels have causal powers they are real ${ }^{23}$, meanings are real, and thus one could if so

\footnotetext{
${ }^{21}$ For example, Eddington (1928, p. x) claimed he had two tables, an ordinary everyday one with colour and substantiality, and a scientific one which is "mostly emptiness" containing "numerous electric charges rushing about with great speed". Ladyman and Ross $(2007$, p. 253$)$ reply that “... both the scientific image and the common-sense image can track real patterns." In metaphorical terms, a physicist can 'see' both of Eddington's tables: the everyday one and the "electric charges" that comprise it. (See also von Bertalanffy, 1955; Chakravartty, 2017.)

${ }^{22}$ Emergence can generate not one level but many, in a sequence of ever higher structures. These extend beyond the body, so mind-environment interactions take place at many levels and over multiple time-scales. Thus perception and meaning occur not just in a single simple loop, but are instead multi-layered. Few stimuli are unambiguous, but with increasingly higher level emergents the possible meanings become progressively fewer.

${ }^{23}$ For example, social structures have causal powers (Elder-Vass, 2010; Lawson, 2013). On causation as central to realism see Chakravartty (2007) and Beni (2020), and for recent arguments
} 
inclined describe reality as meaning. Only a fundamental level would have no meaning, and if there is no fundamental level then the phenomenologists' problem (described by Moss Brender, 2013) that Nature seems essentially meaningless, and thus requires a human observer to add meaning, becomes void.

Put another way, one should make one's definition of 'information' (or whatever) relative to a focal level. What functions as 'information' at that level may emerge from processes at the next lower level that serve as the 'medium' or channel for that information/message/content/pattern. However at that lower level those processes may themselves be fulfilling a functional role within and between the subsystems at that level that serves as 'information' at that level. Semantic information is thus defined most generally as functional interactions between entities within a level. Information (meaning, pattern, etc) is functionality. This accounts for its evolution; if information is structure or pattern then new information emerges ${ }^{24}$ as new structures form and stabilise, i.e. they survive in their environment - which is, after all, what happens in evolutionary progress (e.g. Salthe, 1985; Kauffman, 1993; Rose, 2006, ch. 5; DiFrisco, 2017). ${ }^{25}$

\section{The reality of perception}

Under this new metaphysics can we now make sense of Merleau-Ponty's thesis, as developed by Moss Brender (2013), that all nature is 'perceptual'? We need first to answer questions such as: how exactly does perception work? What are its mechanisms and processes? Through what medium does it occur? Simply invoking magical and mysterious fiats such as 'direct perception' or 'empathic resonance' (Thompson, 2007) does not make the problem go away or solve anything. The use of 'perception' as the model for the genesis of every thing is organism-centric and thus limited in scope to beings with sense organs, which Moss Brender says he is trying to go beyond.

\footnotetext{
that information at higher levels can be causal see DiFrisco (2017), Marshall et al. (2018) and Albantakis et al. (2019).

${ }^{24}$ Novel information (pattern) can emerge when two systems interact such that one system constrains the degrees of freedom of the other (i.e. breaks its symmetry; creates, chooses or imposes a particular form/pattern, or reduces the range of possible forms it can take) and vice versa too (cf. Wilson, 2010; Batterman, 2011; Blachowicz, 2013; Hofkirchner, 2013; Marchetti, 2018). Thus emerge new "patterns of reality" (Primas, 1998, p. 87).

${ }^{25}$ Partially similar worldviews - of multiple ontological levels with (or of) meaning emerging between levels and horizontal causation - have been independently developed by for example Atmanspacher (e.g. 2007, 2015), Jordan \& Ghin (2006) and Jordan et al. (2017) - although with interesting differences of emphasis and detail there is not space to go into here.
} 
In detail: at all levels, including the 'physicochemical', there must be some medium that conveys or communicates between two entities (and a semiotics or semantics to the interaction), which process is merely analogous to 'perception' between an organism and another entity. ${ }^{26}$ In other words, calling all of Nature 'perceptual' is to use the word metaphorically. But if we abstract away from the metaphor and use a more general term such as 'causally connected' (leaving unspecified what the medium is), then the phenomenological theory can be understood as no different from that currently extant within analytic metaphysics (Structural Realism, see $\S 3$ above), namely that every entity is connected to some other in some way. ${ }^{27}$

Another benefit of this systems theory approach is it enables us to make sense of Moss Brender's (2013) symmetry breaking thesis. The problems were first: how does 'perception' work at the eye-less physicochemical level as compared to the organism level? Second, how do mindless and legless entities (such as atoms) move relative to others in order to create a point of view and break symmetry? It's not like an organism deliberately exploring its environment. Third, how can part-whole autopoiesis and active exploration by a 'natural whole' both be examples of symmetry breaking?

Under the more comprehensive worldview of general systems theory, a system exists when entities causally and mutually affect one another. These effects could include changes in their relative spatial positions (hence 'motion'), but can also be described as exchanges of information, leading to 'knowledge' of each other, in a process analogous to 'perception' that creates mutual 'awareness', if not 'understanding' and thus 'meaning' for each entity (and this is what 'symmetry breaking' is). At one level, these rearrangements (if forming or moving toward a new stable synthesis) can be described as the uniting of parts to form a structured whole (autopoiesis). At the next higher level, this whole interacts with other wholes (at that same level), in particular ways determined by their structures; and these wholes too thus may become parts of a new stable autopoietic meta-system. If one insists on using the perception metaphor, ${ }^{28}$ one could say the parts of each whole are 'perceiving' each

${ }^{26}$ Even the famous thesis that quantum wave collapse only occurs when a conscious observer interacts with it has been disproved: any entity will do (Davies, 2006, p. 37).

${ }^{27}$ This is not to say everything is connected directly to everything else and the universe is a single holon - although this is not excluded either. If so, it's likely to be one big 'small-world' network; not all connections are equally efficacious.

${ }^{28}$ As described above, the 'perception' metaphor would be less open to misinterpretation if we all were to use a more neutral term such as 'influence' or 'interact'. For example it seems strange to say that an organism's looking at a chair affects the chair. This might count as an inconsistency in enactivism. However, under multi-level general systems theory we can interpret the process as happening at a higher level and thus over the longer time-scales at which the chair is or at least could be affected via the movements of the organism. (In systems biology a similar process occurs which is referred to as 'ontogenetic niche construction' or 'exogenetic information transmission'; e.g. Barker et al., 2014; Bateson et al., 2017; see also Fabry, 2018.) What is perceived at the higher 
other, just as the two wholes are (at the next higher level) doing the same within their meta-system. ${ }^{29}$ Perception is causal information transfer, and since the latter occurs at all levels, so too does perception.

Thus continental phenomenology can be seen to fit comfortably and consistently within general systems theory, at all levels of Nature. Dynamic systems theory and symmetry breaking alone are not explanation enough, because neither Nature nor the human mind within it are single levels. Physics, systems biology, complexity theory, phenomenology and cognitive science all show that autopoiesis can generate multiple levels of wholes ('real patterns'), not just one; the principle is applicable recursively. In the end, these various conceptual tools all work best when combined, and only by using them together we will get a more comprehensive understanding of our perception of the weird and the wonderful.

Acknowledgements. I thank Sue Blackmore and David Green for comments on earlier versions of the manuscript.

Declaration of Conflicting Interests. The author declares no potential conflicts of interest with respect to the research, authorship, and/or publication of this article.

Funding. The author received no financial support for the research, authorship, and/or publication of this article.

ORCID iD. David Rose https://orcid.org/0000-0001-5581-5141

Open Access This article is distributed under the terms of the Creative Commons Attribution 4.0 International License (http://creativecommons.org/licenses/by/4.0/), which permits unrestricted use, distribution, and reproduction in any medium, provided you give appropriate credit to the original author(s) and the source, provide a link to the Creative Commons license, and indicate if changes were made.

level is thus the longer-term potential significance of the chair, i.e. its 'affordances'. These are therefore not (necessarily) the chair's lower-level appearances such as surface and colour.

${ }^{29}$ In the more formal terms of symmetry breaking, when a system interacts constructively with another its initially relatively equiprobable distribution of meanings becomes a more spiky or uneven distribution; thus its entropy decreases (note it is not a closed system; see Appendix). The same is true of its new co-system, and of the new meta-system they have formed together. These newly dominant meanings/patterns have emerged because they are more functional/significant, in that for example when meeting yet another system they can form a further, even higher-level system which itself may be of even greater significance (i.e. more unambiguous meaningfulness) in other words the whole hierarchical complex can survive/persist for longer (e.g. DiFrisco, 2017). In terms of symmetry: when two systems mutually interact, they both previously had partially broken symmetry, and the resultant meta-system's symmetry is even more broken. 


\section{References}

Albantakis, L., Marshall, W., Hoel, E. \& Tononi, G. (2019). What caused what? A quantitative account of actual causation using dynamic causal networks. Entropy, 21 (5), 459. doi: 10.3390/e21050459.

Annila, A. (2016). On the character of consciousness. Frontiers in Systems Neuroscience, 10:27. doi: 10.3389/fnsys.2016.00027.

Atmanspacher, H. (2007). Contextual emergence from physics to cognitive neuroscience. Journal of Consciousness Studies, 14 (1-2), 18-36.

Atmanspacher, H. (2015). Contextual emergence of mental states. Cognitive Processing, 16, 359-364.

Ball, B., Nagle, F. \& Votsis, I. (2020). (Eds.) Computationalism meets the philosophy of information. Review of Philosophy and Psychology, 11, 507-687.

Barker, G., Desjardins, E. \& Pearce, T. (2014). (Eds.) Entangled Life: Organism and Environment in the Biological and Social Sciences. Dordrecht: Springer.

Bateson, P., Cartwright, N., Dupré, J., Laland, K. \& Noble, D. (2017). New trends in evolutionary biology: biological, philosophical and social science perspectives. Interface Focus, 7. doi: 10.1098/rsfs.2017.0051.

Batterman, R.W. (2011). Emergence, singularities, and symmetry breaking. Foundations of Physics, 41, 1031-1050.

Beni, M.D. (2020). Causal informational structural realism. International Studies in the Philosophy of Science, 33, 117-134.

Bhaskar, R. (1975). A Realist Theory of Science. Leeds: Leeds Books.

Blachowicz, J. (2013). The constraint interpretation of physical emergence. Journal of General Philosophy of Science, 44, 21-40.

Blackmore, S. (2002). There is no stream of consciousness. Journal of Consciousness Studies, 9 (5-6), 17-28.

Braver, L. (2013). On not settling the issue of realism. Speculations, IV, 9-14.

Brooks, D.S., DiFrisco, J., \& Wimsatt, W.C. (2021). (Eds.) Levels of Organization in the Biological Sciences. Cambridge, MA: MIT Press.

Bruineberg, J., Dolega, K., Dewhurst, J. \& Baltieri, M. (in press), The emperor's new Markov blankets. Behavioral and Brain Sciences.

Brüntrup, G. \& Jaskolla, L. (2017). (Eds.) Panpsychism. New York: Oxford University Press.

Bryant, L.R. (2011). The Democracy of Objects. Ann Arbor, MI: Open Humanities Press.

Chakravartty, A. (2007). A Metaphysics for Scientific Realism: Knowing the Unobservable. Cambridge: Cambridge University Press.

Chakravartty, A. (2017). Scientific Ontology: Integrating Naturalized Metaphysics and Voluntarist Epistemology. Oxford: Oxford University Press.

Chalmers, D.J. (2015). Panpsychism and panprotopsychism. In T. Alter, \& Y. Nagasawa (Eds.) Consciousness in the Physical World (pp. 246-276). Oxford: Oxford University Press. Also in Brüntrup \& Jaskolla (2017). 
Chialvo, D.R. (2010). Emergent complex neural dynamics: the brain at the edge. Nature Physics, 6, 744-750.

Clark, A. (2016). Surfing Uncertainty. Prediction, Action, and the Embodied Mind. Oxford: Oxford University Press.

Clowes, R.W. \& Mendonça, D. (2016). Representation redux: Is there still a useful role for representation to play in the context of embodied, dynamicist and situated theories of mind? New Ideas in Psychology, 40, 26-47.

Coates, P. (2007). Experience, action and representations: Critical realism and the enactive theory of vision. Phenomenology and the Cognitive Sciences, 6, 445-462.

Coello, Y. \& Fischer, M.H. (2016). (Eds.) Perceptual and Emotional Embodiment. Foundations of Embodied Cognition Volume 1. Abingdon: Routledge.

Collell, G. \& Fauquet, J. (2015). Brain activity and cognition: a connection from thermodynamics and information theory. Frontiers in Psychology, 6, 818. doi: 10.3389/fpsyg.2015.00818.

Colombo, M. \& Wright, C. (2021). First principles in the life sciences: the freeenergy principle, organicism, and mechanism. Synthese, 198 (Suppl. 14), S3463S3488.

Cooper, R. \& Shallice, T. (2000). Contention scheduling and the control of routine activities. Cognitive Neuropsychology, 17, 297-338.

Davies, P.C.W. (2006). The physics of downward causation. In P. Clayton \& P. Davies (Eds.) The Re-emergence of Emergence: the Emergentist Hypothesis from Science to Religion (pp. 35-52). New York: Oxford University Press.

Deiss, S. (2009). Universal correlates of consciousness. In D. Skrbina (Ed.) Mind that Abides: Panpsychism in the New Millennium (pp. 137-158). Amsterdam: John Benjamins.

DiFrisco, J. (2017). Time scales and levels of organization. Erkenntnis, 82, 795-818.

Eddington, A.S. (1928). The Nature of the Physical World. Cambridge: Cambridge University Press.

Elder-Vass, D. (2010). The Causal Power of Social Structures: Emergence, Structure and Agency. Cambridge: Cambridge University Press.

Elder-Vass, D. (2012). The Reality of Social Construction. Cambridge: Cambridge University Press.

Escobar, J.M. (2012). Autopoiesis and Darwinism. Synthese, 185, 53-72.

Fabry, R.E. (2018). Betwixt and between: the enculturated predictive processing approach to cognition. Synthese, 195, 2483-2518.

Figdor, C. (2021). Shannon + Friston $=$ Content: Intentionality in predictive signalling systems. Synthese, 199, 2793-2816.

Floridi, L. (2011). The Philosophy of Information. Oxford: Oxford University Press.

Fodor, J.A. \& Lepore, E. (2002). The Compositionality Papers. Oxford: Oxford University Press.

Freeman, A. (2006). (Ed.) Consciousness and its Place in Nature: Does Physicalism Entail Panpsychism? Exeter: Imprint Academic. Journal of Consciousness Studies, 13 (whole issue 10-11), 1-285. 
French, S. (2014). The Structure of the World. Oxford: Oxford University Press.

Friston, K. (2010). The free-energy principle: a unified brain theory? Nature Reviews Neuroscience, 11, 127-138.

Gibb, S., Hendry, R.F., \& Lancaster, T. (2019). (Eds.) The Routledge Handbook of Emergence. Abingdon: Routledge.

Gillett, C. (2016). Reduction and Emergence in Science and Philosophy. Cambridge: Cambridge University Press.

Glennan, S. \& Illari, P. (2018). (Eds.) The Routledge Handbook of Mechanisms and Mechanical Philosophy. Abingdon: Routledge.

Glick, D., Darby, G. \& Marmodoro, A. (2020). (Eds.) The Foundation of Reality: Fundamentality, Space, and Time. Oxford: Oxford University Press.

Godfrey-Smith, P. (2020). In the beginning there was information? Studies in History and Philosophy of Biological and Biomedical Sciences, 80, 101239.

Goff, P. (2017). Consciousness and Fundamental Reality. New York: Oxford University Press.

Gomez-Marin, A. (2020). Does your brain exist when unperceived? Review of The Case Against Reality: Why Evolution Hid the Truth from Our Eyes by Donald Hoffman. Constructivist Foundations, 16, 124-128.

Guay, A. \& Sartenaer, O. (2016). A new look at emergence. Or when after is different. European Journal for Philosophy of Science, 6, 297-322.

Hartmann, S. \& Valente, G. (2011). (Eds.) Reduction, emergence and physics. Foundations of Physics, 41, 919-1135.

Heil, J. (2012). The Universe As We Find It. Oxford: Oxford University Press.

Hofkirchner, W. (2013. Emergent Information: A Unified Framework. Singapore: World Scientific.

Hofkirchner, W. \& Schafranck, M. (2011). General system theory. In C. Hooker (Ed.) Philosophy of Complex Systems (pp. 177-194). Amsterdam: Elsevier.

Hüttemann, A. (2003). What's Wrong with Microphysicalism? London: Routledge.

Isaac, A.M.C. (2019). The semantics latent in Shannon information. British Journal for the Philosophy of Science, 70, 103-125.

Isaac, A.M.C. \& Ward, D. (2021). (Eds.) Gestalt phenomenology and embodied cognitive science. Synthese, 198 (Suppl. 9), S2153-S2382.

Jordan, J.S. \& Ghin, M. (2006). (Proto-) consciousness as a contextually emergent property of self-sustaining systems. Mind \& Matter, 4, 45-68.

Jordan, J.S., Cialdella, V.T., Dayer, A., Langley, M.D. \& Stillman, Z. (2017). Wild bodies don't need to perceive, detect, capture or create meaning: they ARE meaning. Frontiers in Psychology, 8, 1149.

Kanai, R., Chang, A., Yu, Y., Magrans de Abril, I., Biehl, M. \& Guttenberg, N. (2019). Information generation as a functional basis of consciousness. Neuroscience of Consciousness, 5 (1), niz016.

Kauffman, S.A. (1993). The Origins of Order: Self Organization and Selection in Evolution. New York: Oxford University Press. 
Kee, H. (2021). Phenomenology and naturalism in autopoietic and radical enactivism: exploring sense-making and continuity from the top down. Synthese, 198 (Suppl. 9), S2323-S2343.

Kesić, S. (2016). Systems biology, emergence and antireductionism. Saudi Journal of Biological Sciences, 23, 584-591.

Kirchhoff, M. (2018). (Ed.) Predictive brains and embodied, enactive cognition. Synthese, 195, 2355-2648.

Koenderink, J. (2014). The All Seeing Eye? Perception, 43, 1-6.

Korbak, T. (2021). Computational enactivism under the free energy principle. Synthese, 198, 2743-2763.

Ladyman, J. \& Ross, D. (2007). Every Thing Must Go. Metaphysics Naturalized. Oxford: Oxford University Press.

Lawson, T. (2013). Emergence and social causation. In R. Groff \& J. Greco (Eds.) Powers and Capacities in Philosophy. The New Aristotelianism. (pp. 285-307). New York: Routledge.

Liang, Z. (2020). Is space discrete? An inquiry into the reality of Planck length and its philosophical implications. Cosmos and History: The Journal of Natural and Social Philosophy, 16, 520-536.

Lombardi, O., Fortin, S. \& Vanni, L. (2015). A pluralist view of information. Philosophy of Science, 82, 1248-1259.

Lombardi, O., Holik, F. \& Vanni, L. (2016). What is Shannon information? Synthese, 193, 1983-2012.

Lombardi, O. \& López, C. (2018). What does 'information' mean in integrated information theory? Entropy, 20, 894.

Maniatis, L.M. (2015). First, believe your eyes. Perception, 44, 1149-1152.

Mann, S.F. (2020). Consequences of a functional account of information. Review of Philosophy and Psychology, 11, 669-687.

Marchetti, G. (2018). Consciousness: a unique way of processing information. Cognitive Processing, 19, 435-464.

Marshall, W., Albantakis, L. \& Tononi, G. (2018). Black-boxing and cause-effect power. PLoS Computational Biology, 14 (4), e1006114.

Matthen, M. (2014). Debunking enactivism. Canadian Journal of Philosophy, 44, 118-128.

Maturana, H.R. \& Varela, F.J. (1980). Autopoiesis and Cognition. $2^{\text {nd }}$ edn. Dordrecht: Reidel.

McHenry, L.B. \& Shields, G.W. (2016). Analytical critiques of Whitehead's metaphysics. Journal of the American Philosophical Association, 483-503. doi: 10.1017/apa.2016.21.

McMahon, D.M. (2001). Enemies of the Enlightenment. The French CounterEnlightenment and the Making of Modernity. New York: Oxford University Press.

Meillassoux, Q. (2006). Après la Finitude. Paris: Editions du Seuil.

Millikan, R. (2004). Varieties of Meaning. Cambridge, MA: MIT Press. 
Millikan, R.G. (2017). Beyond Concepts. Unicepts, Language, and Natural Information. Oxford: Oxford University Press.

Mingers, J. \& Standing, C. (2018). What is information? Toward a theory of information as objective and veridical. Journal of Information Technology, 33, 85104.

Montero, B. (2006). Physicalism in an infinitely decomposable world. Erkenntnis, 64, 177-191.

Moss Brender, L. (2013). Sense-making and symmetry-breaking: Merleau-Ponty, cognitive science, and dynamic systems theory. Symposium: Canadian Journal of Continental Philosophy, 17, 247-273.

Newen, A., De Bruin, L. \& Gallagher, S. (2018). (Eds.) The Oxford Handbook of $4 E$ Cognition. Oxford: Oxford University Press.

Pagden, A. (2013). The Enlightenment and Why It Still Matters. Oxford: Oxford University Press.

Parrondo, J.M.R., Horowitz, J.M., \& Sagawa, T. (2015). Thermodynamics of information. Nature Physics, 11, 131-138.

Pezzulo, G. \& Sims, M. (2021). Modelling ourselves: what the free energy principle reveals about our implicit notions of representation. Synthese, doi: 10.1007/s11229-021-03140-5.

Primas, H. (1998). Emergence in exact natural sciences. Acta Polytechnica Scandinavica, 91, 83-98.

Ramstead, M.J.D., Kirchhoff, M.D., Constant, A. \& Friston, K.J. (2021). Multiscale integration: beyond internalism and externalism. Synthese, 198 (Suppl. 1), S41S70.

Rathkopf, C. (2020). What kind of information is brain information? Topoi, 39, 95102.

Rorot, W. (2021). Bayesian theories of consciousness: a review in search of a minimal unifying model. Neuroscience of Consciousness, 7 (2), 1-14.

Rose, D. (1999). Creativity, intentionality and the conscious/unconscious distinction: a neural theory. Journal of Intelligent Systems, 9, 407-441.

Rose, D. (2006). Consciousness: Philosophical, Psychological and Neural Theories. Oxford: Oxford University Press.

Rose, D. (2012a). Three dimensions of psychosemantics. Gestalt Theory, 34, 259286.

Rose, D. (2012b). Consciousness: distinguishing two types of level and of causation. Physics of Life Reviews, 9, 47-48.

Rose, D. (2018). Review of Shapiro, A.G., \& Todorović, D. (Eds.). The Oxford Compendium of Visual Illusions. Perception, 47, 892-898.

Rose, D. (2021). Perceiving the weird and the wonderful. The mysterious metaphysics of phenomenology, art and science. PsyArXiv, doi: 10.31234/osf.io/8hvmp.

Rose, D. (in preparation-a). George Orwell, objectivity and the reality behind illusions. 
Rose, D. (in preparation-b). Attitudes to vision science and phenomenology.

Rose, D., \& Brown, D. (2015). Idealism and materialism in perception. Perception, 44, 423-435.

Salthe, S.N. (1985). Evolving Hierarchical Systems: Their Structure and Representation. New York: Columbia University Press.

Sankey, H. (2008). Scientific Realism and the Rationality of Science. Aldershot: Ashgate.

Schaffer, J. (2003). Is there a fundamental level? Noûs, 37, 498-517.

Schlicht, T. \& Starzak, T. (2021). Prospects of enactivist approaches to intentionality and cognition. Synthese, 198 (Suppl 1), S89-S113.

Schlosser, M.F. (2018). Embodied cognition and temporally extended agency. Synthese, 195, 2089-2112.

Seager, W. (2016). Theories of Consciousness, Second Edition. Abingdon: Routledge.

Sebold, R. (2014). Continental Anti-Realism: A Critique. London: Rowman \& Littlefield.

Shapiro, L. (2011). Embodied Cognition. London: Routledge.

Silva, M. \& Ferreira, F. (2021). (Eds.) Special issue on radical views on cognition. Synthese, 198 (Suppl. 1), S1-S590.

Silverman, D. (2016). (Ed.) The sensorimotor approach. Journal of Consciousness Studies, 23 (whole issue 5-6), 7-258.

Simon, H.A. \& Ando, A. (1961). Aggregation of variables in dynamic systems. Econometrica, 29, 111-138.

Sims, M. (2021a). How to count biological minds: symbiosis, the free energy principle, and reciprocal multiscale integration. Synthese, 199, 2157-2179, 2181.

Sims, M. (2021b). A continuum of intentionality: linking the biogenic and anthropogenic approaches to cognition. Biology and Philosophy, 36, 51.

Skrbina, D. (2005). Panpsychism in the West. Cambridge, MA: MIT Press.

Skrbina, D. (2009a). (Ed.) Mind that Abides: Panpsychism in the New Millennium. Amsterdam: John Benjamins.

Skrbina, D. (2009b). Introduction. In D. Skrbina (Ed.) Mind that Abides: Panpsychism in the New Millennium (pp. xi-xiv). Amsterdam: John Benjamins.

Skrbina, D. (2009c). Minds, objects, and relations. In D. Skrbina (Ed.) Mind that Abides: Panpsychism in the New Millennium (pp. 361-382). Amsterdam: John Benjamins.

Sparrow, T. (2014). The End of Phenomenology: Metaphysics and the New Realism. Edinburgh: Edinburgh University Press.

Sprevak, M. (2020). Two kinds of information processing in cognition. Review of Philosophy and Psychology, 11, 591-611.

Stendera, M. (2015). Being-in-the-world, temporality and autopoiesis. Parrhesia, 24, 261-284. 
Strawson, G. (2006). Realistic monism: why physicalism entails panpsychism. Journal of Consciousness Studies, 13 (10-11), 3-31. Also in Freeman (2006) and Skrbina (2009a).

Street, S. (2016). Neurobiology as information physics. Frontiers in Systems Neuroscience, 10:90. doi: 10.3389/fsys.2016.00090.

Stubenberg, L. (2016). Neutral monism. In E. N. Zalta (Ed.), The Stanford Encyclopedia of Philosophy, http://plato.stanford.edu/entries/neutral-monism.

Thompson, E. (2007). Mind in Life. Cambridge, MA: Harvard University Press.

Todorović, D. (2020). What are visual illusions? Perception, 49, 1129-1199.

von Bertalanffy, L. (1955). An essay on the relativity of categories. Philosophy of Science, 22, 243-263.

von Uexküll, J. (1909). Umwelt und Innenwelt der Tiere. Berlin: Springer.

Wagemans, J. (2015). Alternatives to veridicalism in vision theory. Perception, 44 (S1), 72.

Ward, D., Silverman, D. \& Villalobos, M. (2017). (Eds.) The varieties of enactivism. Topoi, 36, 365-472.

Werner, G. (2013). Consciousness viewed in the framework of brain phase space dynamics, criticality, and the Renormalization Group. Chaos, Solitons \& Fractals. Nonlinear Science, and Nonequilibrium and Complex Phenomena, 55, 3-12.

Wilson, J. (2010). Non-reductive physicalism and degrees of freedom. British Journal for the Philosophy of Science, 61, 279-311.

Wolin, R. (2019). The Seduction of Unreason. The Intellectual Romance with Fascism from Nietzsche to Postmodernism. $2^{\text {nd }}$ Edition. Princeton: Princeton University Press.

Wright, L. (1973). Functions. Philosophical Review, 82, 139-168.

Zolo, D. (1990). Autopoiesis: critique of a postmodern paradigm. Telos, 23, 61-80. 


\section{Appendix. Systems and information}

In the systems theory context there are several ways in which we can use the term 'information'. These depend (among other things) on whether two systems are assumed to be in continuous mutual interaction, thus forming a higher-level system, or interacting only transiently or in one direction. Thus 'information' might refer to:

(1) The information stored in a system, its internal 'memory' or 'knowledge' (potential for usage), its degree of organization (negentropy), its particular pattern of organization, or the Bayesian priors it holds for interpreting incoming messages.

(2) The information transmitted or communicated in a signal from system A to system B; again, characterised by the amount or the pattern; the potential energy in the signal. Or

(2a) the actual causal effect of that signal on system B.

(3) The emergent novel information or global Gestalt pattern formed when A and B mutually interact, signal or communicate with each other (assuming a new steady-state or persisting dynamic state has been reached). And also

(3a) the effects of the novel emerged state upon the information previously existing in A and B, assessed separately in each (e.g. 'top-down' constraints).

(4) If the interaction was only temporary, the permanent changes to the individual systems' databases that remain after their disconnection or communication cessation.

Conversely, the division introduced in footnote 12 between physical/Shannon and semantic information (Lombardi et al., 2015, 2016; Mingers \& Standing, 2018; Ball et al., 2020) has recently been challenged in various ways (for example by Isaac, 2019; Mann, 2020; Rathkopf, 2020; Sprevak, 2020), raising the prospect for a more unified interpretation.

Moreover, because Landauer's principle posits an identity or interconvertibility between information and energy, several researchers have recently applied thermodynamic principles to the neural, conscious and/or cognitive processing of information. Thus biological systems in particular are not closed; they take free energy from their surroundings to keep themselves in thermodynamic balance with their environment (Annila, 2016). As the environment changes, stepwise phase transitions in state space may occur, which in the long run optimise survival by tracking the borders of criticality between chaos and stability (Kaufmann, 1993; Chialvo, 2010; Werner, 2013). Thus as systems self-organize, they increase orderliness within themselves at the expense of order in the environment (with an overall decrease in order/free energy in total), and this increase in intrasystem order creates (or just is) novel information (Collell \& Fauquet, 2015; Parrondo et al., 2015; Street, 2016).

There is not space here to review the veritable storm of publications currently appearing around the 'principle of free energy minimization' (Friston, 2010); for recent reviews of its relationship to autopoiesis, enactivism, Bayesianism, cognition and 'predictive processing' (i.e. top-down hypothesis generation) see for example Pezzulo and Sims (2021), Ramstead et al. (2021), Rorot (2021) and Bruineberg et al. (in press). It has been claimed to account for the appearance of ontological boundaries around cognizing systems at multiple scales (e.g. Ramstead et al., 2021; Sims, 2021a). However, it has also been suggested that this approach is ultimately reductionist and single-levelled, in the sense of $\$ 3.1$ above, since everything is to be accounted for in terms of this one principle (Fabry, 2018, p. 2510; see also Colombo \& Wright, 2021).

In addition, this applies to Landauer's information as energy principle too. For example Collel and Fauquet (2015) and Street (2016) cite glucose and $\mathrm{O}_{2}$ carried to nerve cells by the blood as the 
source of the free energy that is converted into information. But the structures of relevance to (human everyday) consciousness are at higher levels. Are molecular mechanisms such as ATP generation and consumption sufficient to support and explain the relevant (semantic informationbearing) improvements in flow patterns of action potentials (or whatever is the relevant level for consciousness)? Or does the organization of a higher level (for example the pattern of connections in a neural network) instead arise only (or also) from the consumption of free energy/entropy released by disorganizing other, neighbouring neural networks? Is 'free energy' equally relevant for a higher-level system's learning and perceptual functions whether it originates directly from the system's internal fundamental physics, and/or from its biochemical metabolism — or instead (or as well) from the randomization or de-structuring of other systems at the same higher level?

So it remains to be seen whether and how the application of an apparently physical conception of negentropy as energy can be translated into or shown to be equivalent to semantic understandings of the term 'information'. At first glance, the former appears to apply best to within-system information (structure, organization), whereas semantic information involves effective, causal transmission or read-out between systems (meaning 1 versus meaning 2, above) - but this will of course almost certainly turn out to be an oversimplification (cf. also Godfrey-Smith, 2020, and Figdor, 2021).

Putting the issue of information emergence and creation more simply: brand new meaning/information emerges when the mutual interaction between two (or more) communicating systems creates a novel pattern across them both that does not occur when the systems are in isolation. New meaning can also emerge within a receiving system alone when iterative search mechanisms settle onto a compromise that is neither exactly the input nor any of the stored patterns, thus generating a novel 'interpretation' that did not exist in the system before (cf. pattern recognition processes that show creativity and imagination: Rose, 1999; Kanai et al., 2019).

Put yet another way, in typical two-way interactions, both systems previously had partially broken symmetry, and the resultant meta-system's symmetry is even more broken.

Finally, there are several ways to envisage the systems concept. We tend to construct mental models or images to help us understand situations, and which ones we use depend on our academic training. Physicists may be thinking in terms of quantum entanglements, (bio)chemists in terms of atomic/molecular complexes (such as receptor- or enzyme-ligand binding), biologists in terms of cell-cell communication or animal pairings, for ecologists it is species interactions, for cognitive scientists it is symbol/representation manipulations by processing rules, for (social) psychologists it is discourse (verbal and other), empathy or theory of mind, economists think in terms of competing companies or company sub-structuring into departments and line managers, sociologists in terms of social classes or groupings, politicians in terms of nation states, cultural exchanges and wars, engineers in terms of networks and hubs (e.g. power, communication, transport) ... . So when it comes to applying a general theory of communication or semiotics, the possibilities have to be prespecified explicitly if we are to follow the same mental model as the author. Another variable is relative motility. Are the systems we are discussing independent, mobile agents (as Moss Brender, 2013, posits as 'the' mechanism for breaking symmetry, given phenomenology's universal 'pointof-view' requirement)? If so, do they have to come into proximity to communicate? Does this require physical contact or can action-at-a-distance take place? Can information be broadcast globally in all directions or must it be directed at (or tailored for) a particular recipient? Lack of clarity on these points may underlie communication problems between researchers, even within the same discipline! 